\title{
A polyp from another polyp
}

\author{
Vincent Kuo $M D^{1}$, Wareef Kabbani $M D^{2}$, Jeffrey Linder $M D^{1}$
}

$\mathrm{A}_{\mathrm{a}+\mathrm{n}^{\mathrm{n}}}$ n 86-year-old woman presented for initial evaluation after an abnormal positron emission tomography (PET) scan revealed activity in the sigmoid colon suggestive of malignancy. She had a medical history of chronic obstructive pulmonary disease with a recent lung nodule that was found to be malignant. As part of her workup, a PET scan was performed and the results prompted evaluation by a gastroenterologist. The patient had never undergone a colonoscopy and denied any gastrointestinal symptoms. Colonoscopy revealed a sessile polyp $1 \mathrm{~cm}$ in size in the cecum, which was removed by snare electrocautery. There was an additional $1 \mathrm{~cm}$ pedunculated polyp in the sigmoid colon; arising from the stalk of the pedunculated polyp was another sessile polyp $7 \mathrm{~mm}$ in size. There was a $1 \mathrm{~cm}$ segment of normal-appearing mucosa on the stalk separating the two polyps (Figure 1A). Both were removed by snare electrocautery at the base of the stalk.

Pathology revealed the cecal polyp to be a tubular adenoma. The sigmoid polyp was a tubulovillous adenoma; the tumour emanating from the stalk was a low-grade, moderately differentiated adenocarcinoma with invasion into the submucosa (Figure 1B). There were negative margins within $1 \mathrm{~mm}$ of the polypectomy site, and no angiolymphatic or perineural invasion (Figure 1C). Immunostains were negative for transcription termination factor-1 and positive for CDX-2, which was consistent with a primary colorectal adenocarcinoma. The patient returned for follow-up and denied any complaints. She is scheduled to undergo a repeat colonoscopy in six months to ensure complete removal of the lesion.

There have been studies determining the utility of a PET scan in detecting colon polyps. Often, patients undergo a PET scan as part of a malignancy workup and may incidentally have suspicious lesions apparent in the colon. This is due to increased glucose metabolism and fluorodeoxy glucose uptake in colon adenomas. Studies have suggested that the degree of uptake is proportional to the degree of dysplasia in an adenoma (1). Correlation with colonoscopic findings generally shows that polyps $>10 \mathrm{~mm}$ in size have a higher detection rate on PET. The pathology of the polyps can include hyperplastic, tubular adenoma, tubulovillous adenoma and carcinoma (2). Uptake on PET scan can have a focal or nonfocal pattern. Nonfocal uptake often represents a physiological variant and can be a nonspecific finding. Review of the literature suggests that a focal pattern of colorectal uptake can be associated with a $65 \%$ chance of identifying a malignant or premalignant lesion (3).

DISCLOSURES: The authors have no financial disclosures or conflicts of interest to declare.

\section{REFERENCES}

1. Yelsangikar A, Pendsey S, Pradeep K, et al. Incidental colorectal polyps in positron emission tomography. Indian J Nucl Med 2012;27:30-2.

2. Gollub MJ, Akhurst T, Markowitz AJ, et al. Combined CT colonography and 18F-FDG PET of colon polyps: Potential technique for selective detection of cancer and precancerous lesions. Gastrointest Imag 2007;188:130-8.

3. Treglia G, Calcagnia ML, Rufini V, et al. Clinical significance of incidental focal colorectal (18)F-fluorodeoxyglucose uptake: Our experience and a review of the literature. Colorect Dis 2012;14:174-80.
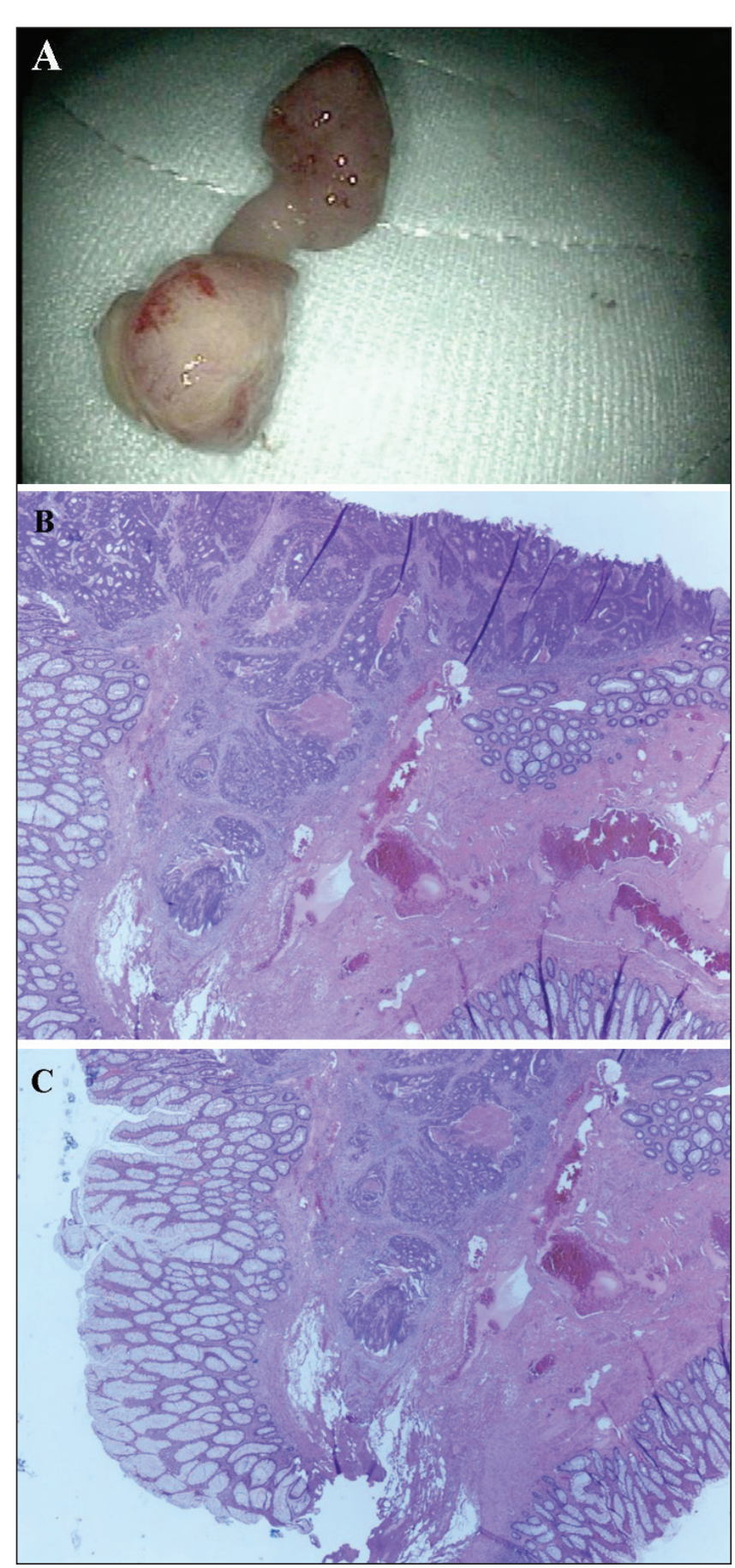

Figure 1) A Sigmoid polyp. B Adenocarcinoma with submucosal invasion. C Polypectomy site with negative margins. Hematoxylin and eosin stain, original magnification $\times 20$

\footnotetext{
${ }^{1}$ Department of Gastroenterology; ${ }^{2}$ Department of Pathology, Methodist Dallas Medical Center, Dallas, Texas, USA

Correspondence: Dr Vincent Kuo, Methodist Dallas Medical Center, Department of Gastroenterology, Dallas, Texas, USA.

Telephone 469-233-2807, e-mail vincentkuo8@gmail.com
}

Received for publication September 9, 2013. Accepted September 15, 2013 


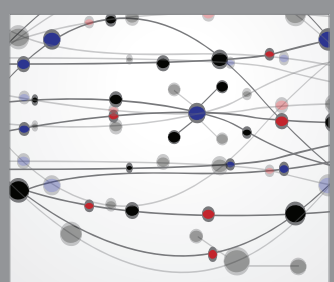

The Scientific World Journal
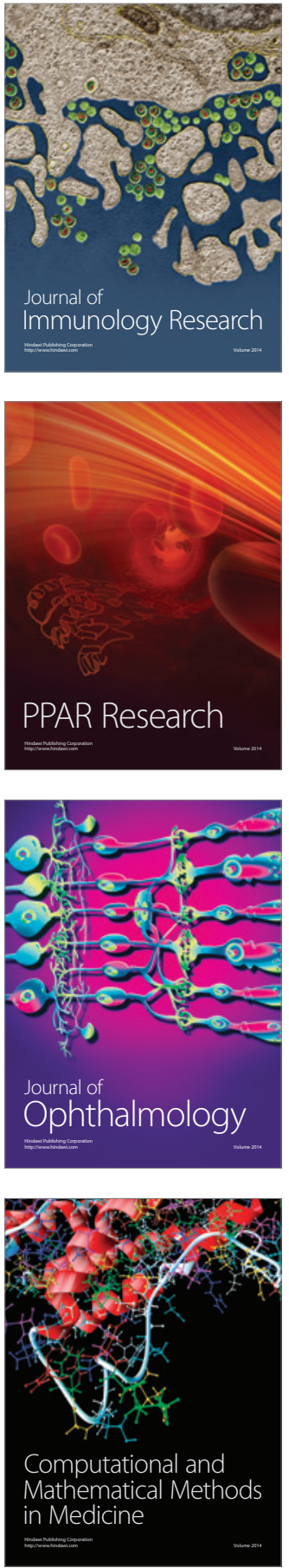

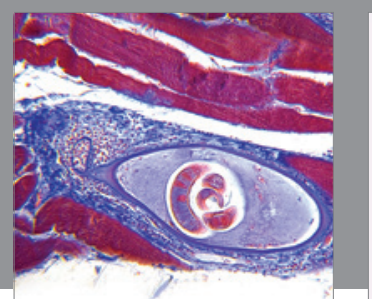

Gastroenterology Research and Practice

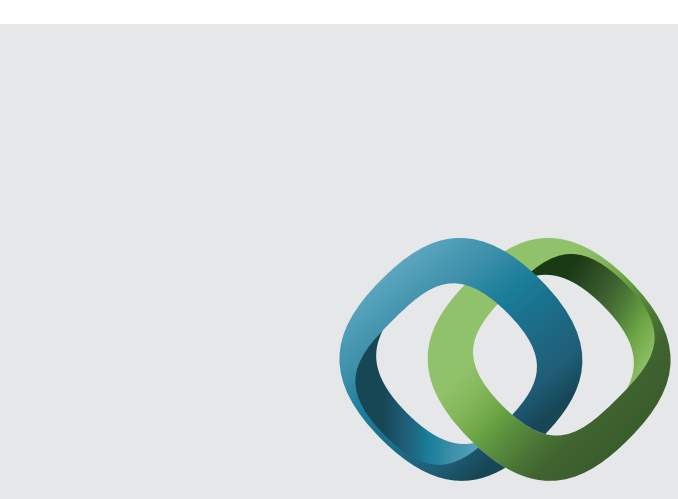

\section{Hindawi}

Submit your manuscripts at

http://www.hindawi.com
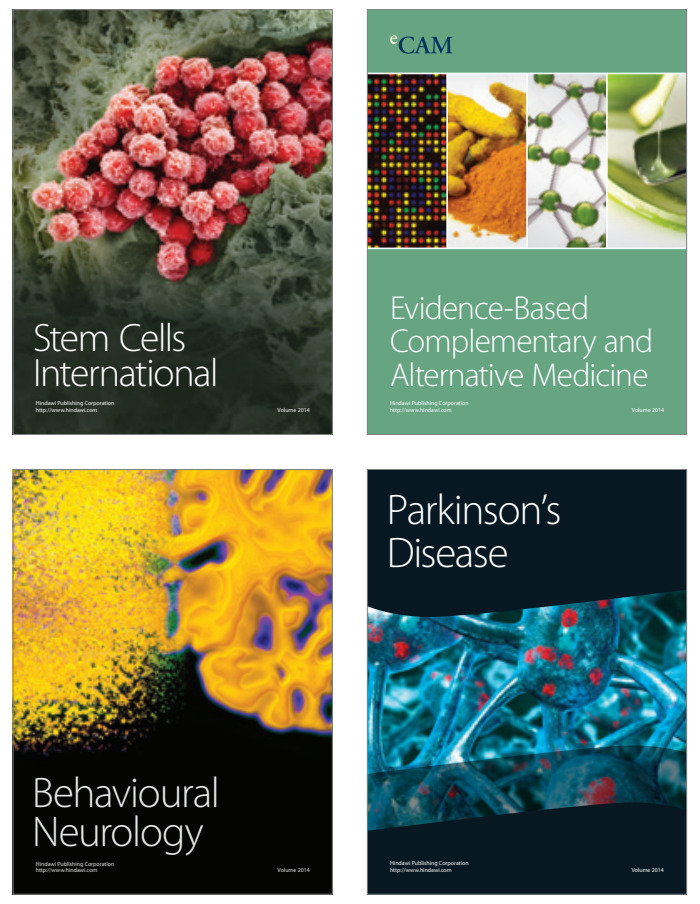
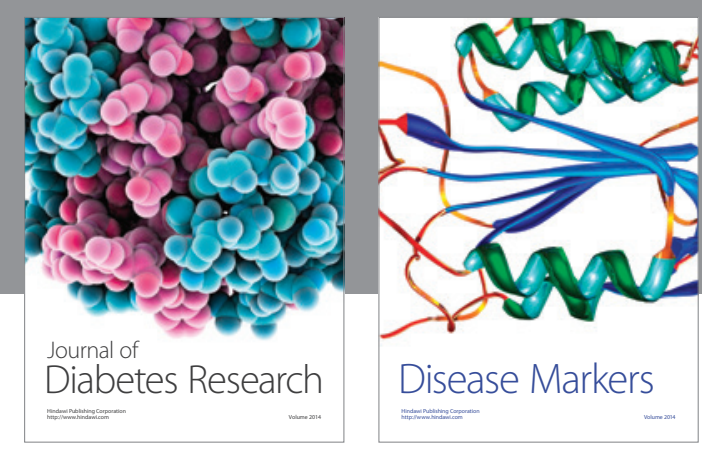

Disease Markers
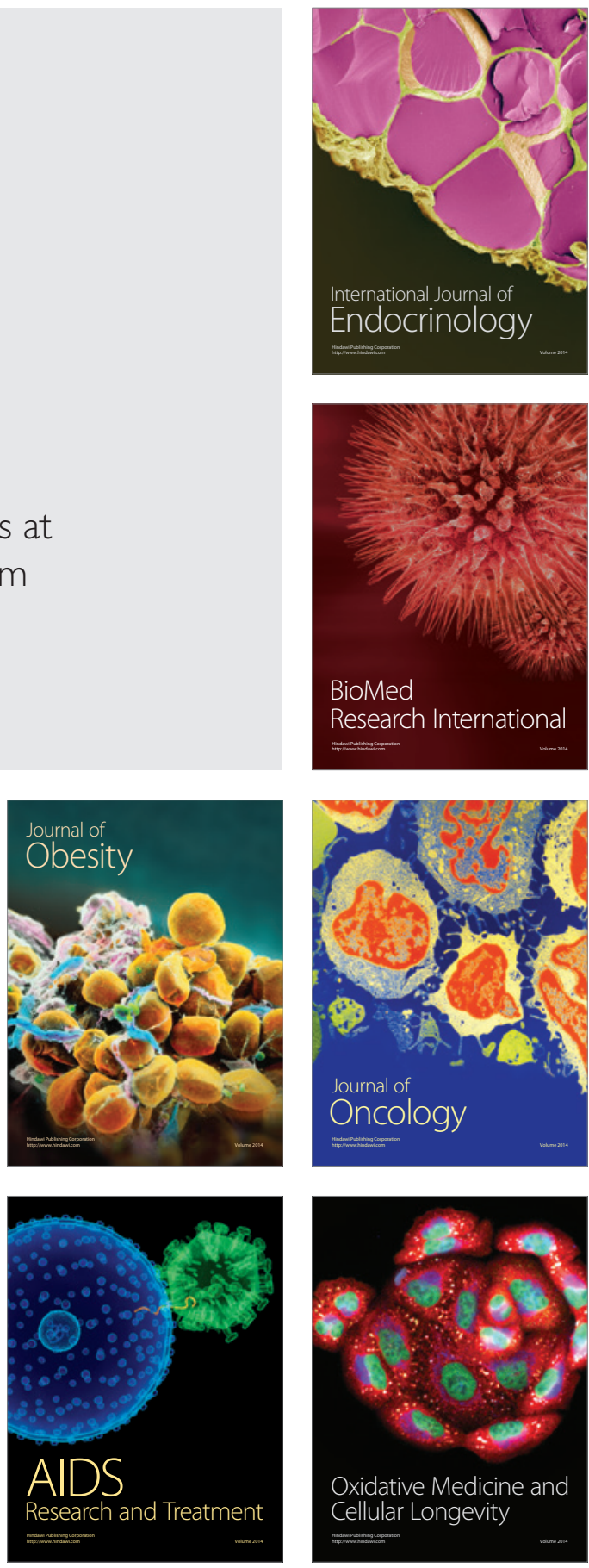